Article

\title{
Anti-Inflammatory and Gastroprotective Roles of Rabdosia inflexa through Downregulation of Pro-Inflammatory Cytokines and MAPK/NF- $\kappa B$ Signaling Pathways
}

\author{
Md Rashedunnabi Akanda ${ }^{1,2}$, In-Shik Kim ${ }^{1}$, Dongchoon Ahn ${ }^{1}$, Hyun-Jin Tae ${ }^{1}$, \\ Hyeon-Hwa Nam ${ }^{3}$, Byung-Kil Choo ${ }^{3}$, Kyunghwa Kim ${ }^{4}$ and Byung-Yong Park ${ }^{1, *}$ \\ 1 College of Veterinary Medicine and Bio-safety Research Institute, Chonbuk National University, Iksan 54596, \\ Korea; rashed.mvd@gmail.com (M.R.A.); iskim@jbnu.ac.kr (I.-S.K.); ahndc@jbnu.ac.kr (D.A.); \\ hjtae@jbnu.ac.kr (H.-J.T.) \\ 2 Department of Pharmacology and Toxicology, Sylhet Agricultural University, Sylhet 3100, Bangladesh \\ 3 Department of Crop Science and Biotechnology, Chonbuk National University, Jeonju 54896, Korea; \\ hh_hh@jbnu.ac.kr (H.-H.N.); bkchoo@jbnu.ac.kr (B.-K.C.) \\ 4 Department of Cardiothoracic Surgery, Research Institute of Clinical Medicine, Chonbuk National \\ University, Jeonju 54907, Korea; tcskim@jbnu.ac.kr \\ * Correspondence: parkb@jbnu.ac.kr; Tel.: +82-63-850-0961
}

Received: 23 January 2018; Accepted: 13 February 2018; Published: 14 February 2018

\begin{abstract}
Globally, gastric ulcer is a vital health hazard for a human. Rabdosia inflexa (RI) has been used in traditional medicine for inflammatory diseases. The present study aimed to investigate the protective effect and related molecular mechanism of RI using lipopolysaccharide (LPS)-induced inflammation in RAW 246.7 cells and $\mathrm{HCl} / \mathrm{EtOH}$-induced gastric ulcer in mice. We applied 3-(4,5-dimethyl-thiazol-2-yl)-2,5-diphenyltetrazolium bromide (MTT), nitric oxide (NO), reactive oxygen species (ROS), histopathology, malondialdehyde (MDA), quantitative real-time polymerase chain reaction (qPCR), immunohistochemistry (IHC), and Western blot analyses to evaluate the protective role of RI. Study revealed that RI effectively attenuated LPS-promoted $\mathrm{NO}$ and ROS production in RAW 246.7 cells. In addition, RI mitigated gastric oxidative stress by inhibiting lipid peroxidation, elevating $\mathrm{NO}$, and decreasing gastric inflammation. RI significantly halted elevated gene expression of pro-inflammatory cytokines such as tumor necrosis factor- $\alpha$ (TNF- $\alpha)$, interleukin-1 $\beta$ (IL-1 $\beta)$, interleukin-6 (IL-6), inducible nitric oxide synthetase (iNOS), and cyclooxygenase-2 (COX-2) in gastric tissue. Likewise, RI markedly attenuated the mitogen-activated protein kinases (MAPKs) phosphorylation, COX-2 expression, phosphorylation and degradation of inhibitor kappa B $(\mathrm{I} \kappa \mathrm{B} \alpha)$ and activation of nuclear factor kappa B (NF- $\mathrm{kB})$. Thus, experimental findings suggested that the anti-inflammatory and gastroprotective activities of RI might contribute to regulating pro-inflammatory cytokines and MAPK/NF- $\mathrm{KB}$ signaling pathways.
\end{abstract}

Keywords: Rabdosia inflexa; inflammation; gastric ulcer; cytokines; MAPK; NF-кB

\section{Introduction}

Alcohol consumption is a recognized risk factor for human health. The most common diseases include infectious diseases, gastric ulcer, cancer, diabetes, and liver and pancreas disease caused by alcohol consumption either partially or entirely [1]. The pathogenesis of gastric ulcer is complicated and multifactorial; it is usually caused by an acute imbalance between gastric mucosal integrity and mucosal immunity [2]. Usually, ethanol is absorbed through the intestinal wall and metabolized in the liver in different ways: oxidation by alcohol dehydrogenase (ADH), cytochrome P450 2E1 
(CYP2E1), and catalase enzymes. All the processes intensify to form acetaldehyde and then acetate by aldehyde dehydrogenase (ALDH). Alcohol metabolism with ADH enhances the generation of reduced forms of nicotinamide adenine dinucleotide (NADH), but production of CYP2E1 continues to produce free radical. Acetaldehyde and free radicals combine with cell compounds and disturb cell physiology [3]. Consequently, oxidative stress plays a crucial role in the pathogenesis of alcoholic tissue damage and increases lipid peroxidation, which injures capillary endothelial cells and increases cellular permeability [4] that are involved in the DNA damage of gastric mucosal epithelial cells [5]. Although the complete mechanism of alcohol-induced gastric mucosal damage has not been fully disclosed, evidence shows that oxidative stress and neutrophil infiltration are associated with the development of acute gastritis [6,7].

Lipopolysaccharide (LPS), a bacterial endotoxin, is commonly used as an inducer of the macrophage cell lineage, acting through Toll-like receptor 4 (TLR4), which activates the mitogen-activated protein kinases (MAPKs) signaling cascades and the pathway that triggers nuclear factor kappa $\mathrm{B}(\mathrm{NF}-\mathrm{KB})[8,9]$. MAPKs are the important signaling pathway and play a crucial regulatory role in both adapted and innate immune response [10]. Ethanol-induced oxidative stress stimulates the release of reactive oxygen species (ROS). ROS are recognized as the second messenger to initiate the redox-sensitive signal-transduction pathway with MAPK cascade and are linked with downstream transcription factor: NF- $\kappa B$ [11]. ROS mediate stimulation of inhibitor kappa B (IкB) kinase, which induces proteasomal breakdown of $\mathrm{I} \kappa \mathrm{B} \alpha$ and activates NF- $\kappa B$. NF- $\kappa B$ is a transcription factor that binds to $k-\beta$ motifs in the promoters of target genes and triggers transcription of inflammatory cytokines and chemokines [12].

The therapeutic and biological activities of indigenous plants and their active compounds have potential importance for their capability to manage and treat many inflammatory and immunomodulatory diseases [13]. Rabdosia inflexa (RI), a perennial shrub, is a member of the lamiaceae family, which is cosmopolitan and cultivated throughout Northeast China, the Korean peninsula, and Japan. In South Korea, RI, locally known as "sanbakha", has been used as folk medicine for treating gastrointestinal inflammation and pain. Previously, RI and its active compounds such as inflexin and inflexinol have been reported for pancreatitis and anti-cancer effect [14-16]. Based on its traditional uses and biological activities, the study investigated its anti-inflammatory and gastroprotective activity and its possible molecular mechanisms in both RAW 264.7 cells and $\mathrm{HCl} / \mathrm{EtOH}$-induced gastric ulcer in mice.

\section{Results}

\subsection{Analysis of Total Phenolic and Flavonoid Contents of Rabdosia inflexa (RI)}

Phenolic and flavonoid contents are the secondary metabolites of a plant, having a wide range of biological activities and usually antioxidant properties. The total phenolic and flavonoid content of RI were investigated and presented in Table 1 . The total phenolic and flavonoid content of RI were $143.288 \pm 1.68 \mathrm{mg} / \mathrm{g}$ gallic acid and $256.301 \pm 1.40 \mathrm{mg} / \mathrm{g}$ rutin equivalent, respectively.

Table 1. Total phenolic and flavonoid content of Rabdosia inflexa (RI).

\begin{tabular}{cccc}
\hline Plant Extract & $\begin{array}{c}\text { Total Phenolic (mg } \\
\text { GAE/g Extract) }\end{array}$ & $\begin{array}{c}\text { Total Flavonoid (mg } \\
\text { RU/g Extract) }\end{array}$ & Total Yield (\%) \\
\hline RI & $143.288 \pm 1.68$ & $256.301 \pm 1.40$ & 27.13 \\
\hline
\end{tabular}

Note: Gallic acid and rutin were used as standards. Results are expressed in milligrams of gallic acid equivalent per gram of extract sample (mg GAE/g) and $\mathrm{mg}$ of rutin equivalent per gram of extract sample (mg RU/g).

\subsection{Effect of RI on Viability and Morphology of RAW 264.7 Cells}

The present study measured the anti-inflammatory ability of RI extract using RAW 264.7 cells on LPS-induced inflammation using MTT assay. To investigate the cytotoxicity and cell viability of RI, 
RAW 264.7 cells were treated with different concentrations of RI (50, 100, 200, 400, and $800 \mu \mathrm{g} / \mathrm{mL})$ for $24 \mathrm{~h}$. Among the concentrations, RI $(800 \mu \mathrm{g} / \mathrm{mL})$ significantly reduced the cell viability (Figure 1a). However, the cell viability did not significantly alter after co-treatment with LPS $(0.5 \mu \mathrm{g} / \mathrm{mL})$ and RI (100, 200, and $400 \mu \mathrm{g} / \mathrm{mL}$ ) for $24 \mathrm{~h}$ (Figure 1b). As shown in Figure 1c, LPS markedly induced morphological changes of RAW 264.7 cells after $24 \mathrm{~h}$ of treatment, which was consequently improved by the treatment with RI. Thus, results proposed that RI has not affected the viability and morphology of RAW 264.7 cells and it could be due to the anti-inflammatory effect of RI.

(a)

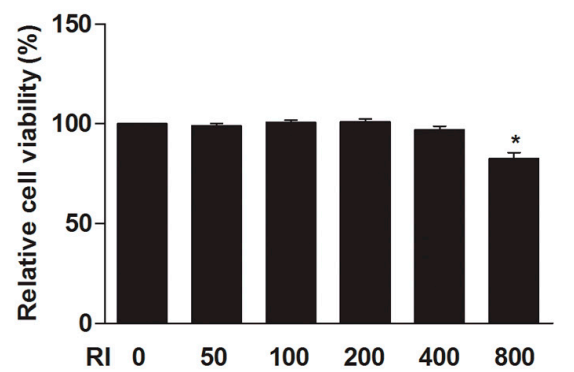

(b)

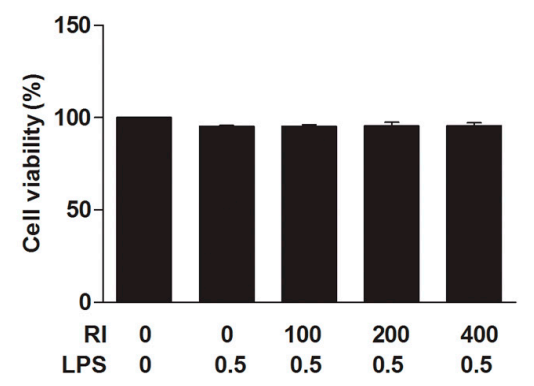

(c)

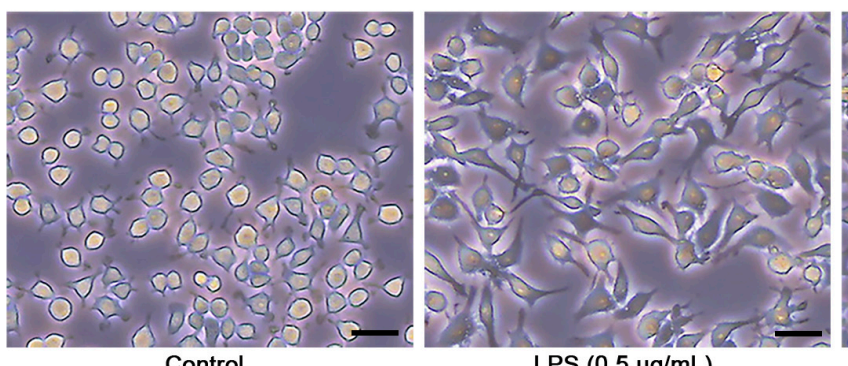

Control

LPS $(0.5 \mu \mathrm{g} / \mathrm{mL})$

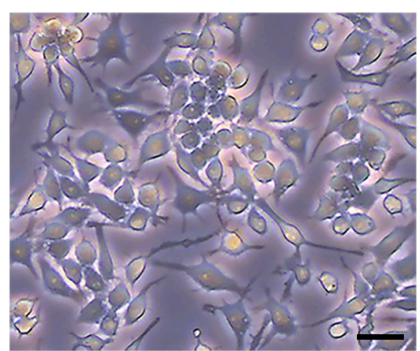

LPS+RI $(200 \mu \mathrm{g} / \mathrm{mL})$

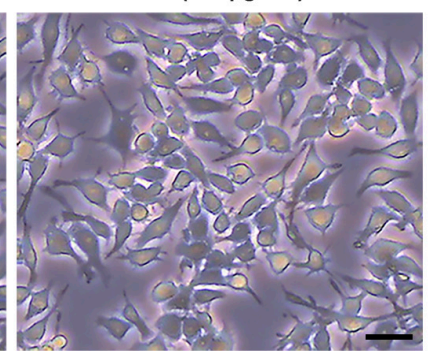

LPS+RI $(400 \mu \mathrm{g} / \mathrm{mL})$

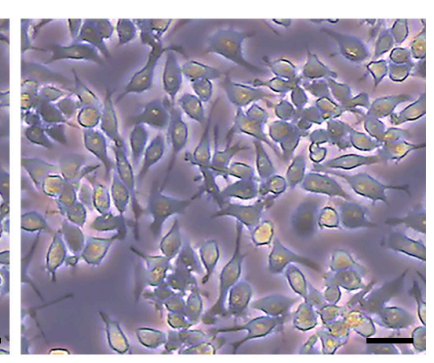

LPS+RI $(100 \mu \mathrm{g} / \mathrm{mL})$

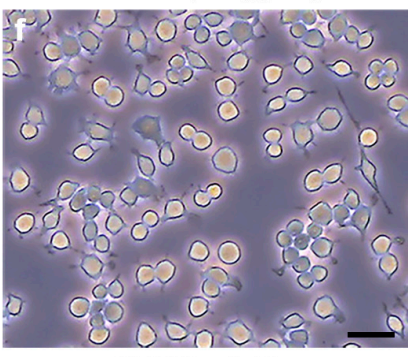

$\mathrm{RI}(400 \mu \mathrm{g} / \mathrm{mL})$

Figure 1. Protective role of Rabdosia inflexa (RI) on: (a) cytotoxicity; (b) cell viability; and (c) morphological alteration in RAW 264.7 cells were measured by MTT assay. Cells were pretreated with various concentration of RI $(100,200$, and $400 \mu \mathrm{g} / \mathrm{mL})$ for $1 \mathrm{~h}$, followed by co-treatment with RI and LPS $(0.5 \mu \mathrm{g} / \mathrm{mL})$ for another $24 \mathrm{~h}$. Cell morphology was visualized by optical microscopy (scale bar $200 \mu \mathrm{m}) .{ }^{*} p<0.05$ when compared with the control. Data are expressed as mean $\pm \mathrm{SEM}$ of three independent experiments.

\subsection{RI Attenuated the LPS-Induced NO and ROS Production in RAW 264.7 Cells}

In LPS-treated cells, there was a marked increase $(p<0.05)$ in NO and ROS production as compared to the control. Conversely, co-treatment with the RI significantly reduced $(p<0.05)$ the $\mathrm{NO}$ and ROS production in a dose-dependent manner (Figure 2a,b). Together, RI suppressed the LPS-induced inflammatory response by preventing NO and intracellular ROS production in RAW 264.7 cells. 
(a)

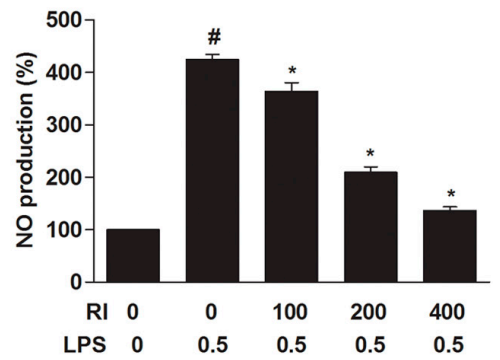

(c)

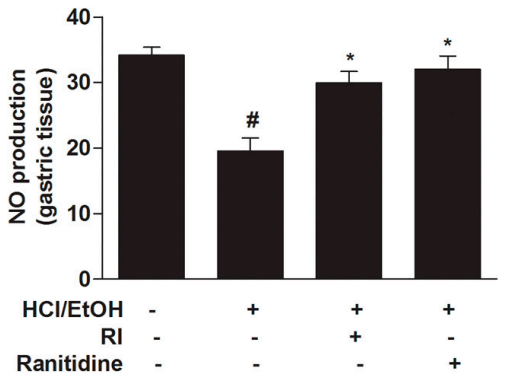

(b)

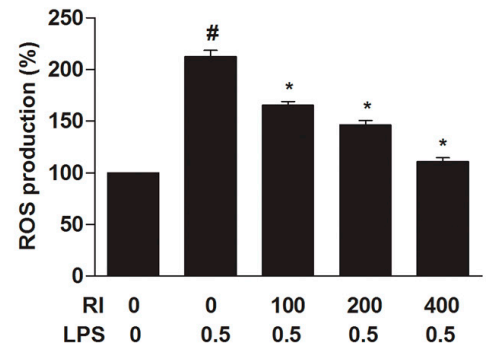

(d)

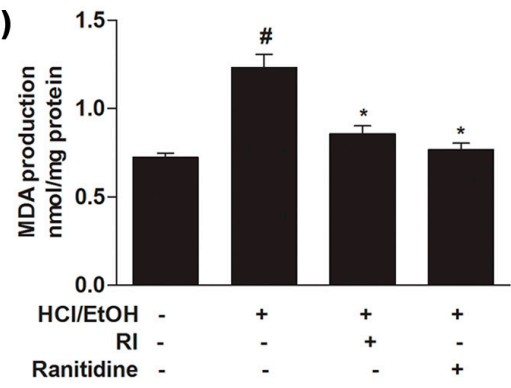

Figure 2. Protective role of RI on NO, intracellular ROS and MDA production in RAW 264.7 cells and gastric tissue. (a) NO; and (b) ROS production was measured by Griess and ROS-Glo $\mathrm{H}_{2} \mathrm{O}_{2}$ assays in RAW 264.7 cells (upper panel). Cells were pretreated with various concentration of RI (100, 200, and $400 \mu \mathrm{g} / \mathrm{mL})$ for $1 \mathrm{~h}$, followed by co-treatment with RI and LPS $(0.5 \mu \mathrm{g} / \mathrm{mL})$ for another $24 \mathrm{~h}$. (c) NO; and (d) MDA production in gastric tissue were measured by Griess and TBARS assays (lower panel). Mice were pretreated for $1 \mathrm{~h}$ with RI (400 mg/kg) and Ranitidine $(40 \mathrm{mg} / \mathrm{kg})$. After $1 \mathrm{~h}, \mathrm{HCl} / \mathrm{EtOH}(10$ $\mu \mathrm{L} / \mathrm{g}$ ) was given orally. \# $p<0.05$ when compared with the control and * $p<0.05$ when compared with LPS and $\mathrm{HCl} / \mathrm{EtOH}$. Data are expressed as mean \pm SEM.

\subsection{RI Improved the Gross and Histopathology of Gastric Tissue}

The recent study investigated the gastroprotective effect of $\mathrm{RI}$ in $\mathrm{HCl} / \mathrm{EtOH}$-induced gastric ulcer in mice. $\mathrm{HCl} / \mathrm{EtOH}$-induced severe gastric damage, which was notably attenuated by RI pretreatment (Figure 3a, upper panel). In addition, the histological study confirmed that the stomach had the normal structure of mucosa in control group. Besides, in the $\mathrm{HCl} / \mathrm{EtOH}$-treated mice, epithelial destruction and inflammatory cells infiltration were found in the mucosa and submucosal area. However, RI and ranitidine-treated groups markedly improved the histopathological changes as compared to $\mathrm{HCl} / \mathrm{EtOH}$-treated group (Figure 3a, lower panel). These data are well correlated with the protective abilities of RI against gastric ulcer. Likewise, the gross and histological lesions index of gastric tissue was significantly reduced $(p<0.05)$ by pretreatment with RI and ranitidine treated groups than in $\mathrm{HCl} / \mathrm{EtOH}$-induced gastric ulcer mice (Figure $3 \mathrm{~b}, \mathrm{c}$ ).

\subsection{RI Regulated the NO and MDA Production in Gastric Tissue}

To evaluate the oxidative stress level, the NO and MDA production was measured in gastric tissue. After inducing gastric injury, $\mathrm{HCl} / \mathrm{EtOH}$ significantly $(p<0.05)$ decreased $\mathrm{NO}$ and increased MDA production. Overall, pretreatment with the RI effectively $(p<0.05)$ increased and decreased the $\mathrm{NO}$ and MDA production as related to standard drug ranitidine, respectively (Figure 2c,d). Therefore, results evidently reveal that RI reduced the oxidative stress in $\mathrm{HCl} / \mathrm{EtOH}$-stimulated gastric ulcer for its strong anti-oxidant and anti-inflammatory capacity. 
(a)

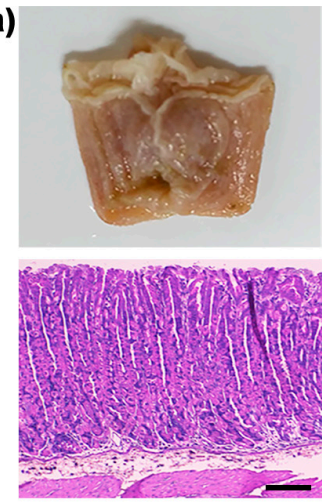

Control
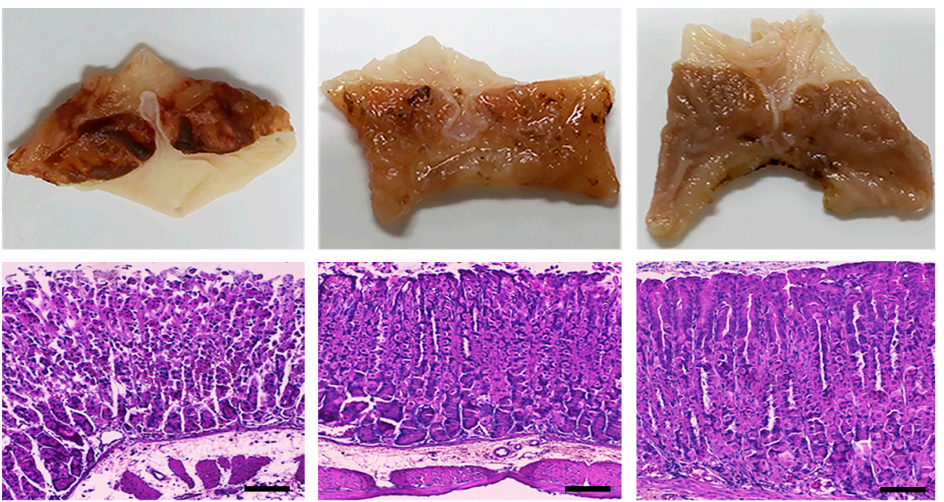

$\mathrm{HCl} / \mathrm{EtOH}$

(b)

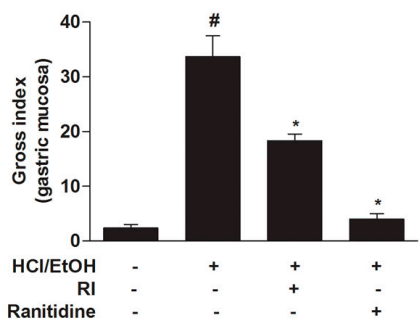

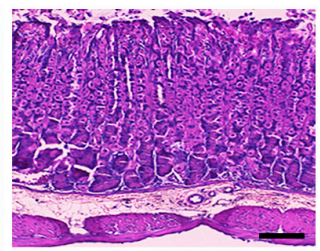

HCl/EtOH+RI

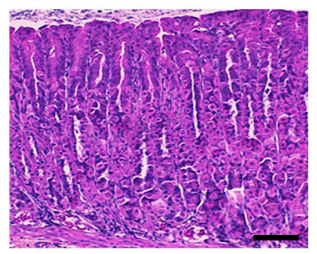

HCl/EtOH+Ranitidine

(c)

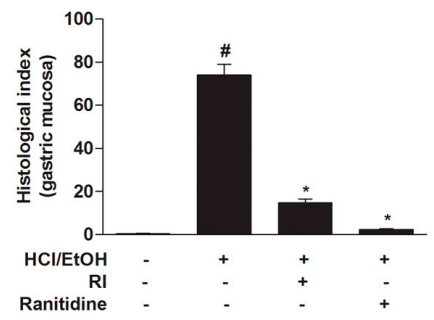

Figure 3. Protective role of $\mathrm{RI}$ on $\mathrm{HCl} / \mathrm{EtOH}$-induced gastric damage in mice: (a) gross lesion (upper panel) and histological lesion (lower panel) (scale bar. $200 \mu \mathrm{m}$ ); (b) gross lesion index; and (c) histological index. \# $p<0.05$ when compared with the control and ${ }^{*} p<0.05$ when compared with $\mathrm{HCl} / \mathrm{EtOH}$. Data are expressed as mean $\pm \mathrm{SEM}$.

\subsection{RI Suppressed the Activation Pro-Inflammatory Cytokines in Gastric Tissue}

Pro-inflammatory cytokines play a fundamental role in various types of inflammation. To elucidate the protective role of RI, the gene expression of pro-inflammatory cytokines was examined in the glandular stomach samples by qPCR analysis. The gene expression level of TNF- $\alpha, I L-1 \beta$, $I L-6$, iNOS, and COX-2 were gradually upregulated $(p<0.05)$ in the $\mathrm{HCl} / \mathrm{EtOH}$-treated group as compared to the control, whereas pretreatment with RI and ranitidine groups significantly $(p<0.05)$ downregulated the cytokines expression level than in the $\mathrm{HCl} / \mathrm{EtOH}$-treated group (Figure 4a-e). Thus, data suggest that RI inhibited the gene expression of pro-inflammatory cytokines in gastric tissue and thereby mitigated the gastric inflammation.

\subsection{RI Inhibited the COX-2 Expression in Gastric Tissue}

It is recognized that elevated expression of COX-2 plays a vital role in the inflammatory process and previous study has revealed that $\mathrm{HCl} / \mathrm{EtOH}$ strongly activates COX-2 expression in gastric tissue [17]. COX-2 expression in the gastric mucosal epithelial cells was revealed by immunohistochemical staining analysis. As observed, COX-2 was slightly expressed in the normal control gastric mucosal epithelial cells; in contrast, $\mathrm{HCl} / \mathrm{EtOH}$ increased the $\mathrm{COX}-2$ expression of gastric mucosal epithelial cells, which was mostly observed in the gastric mucosal inflammatory area (Figure 5a). The expression of COX-2 was markedly $(p<0.05)$ blocked by the pretreatment of RI as related to the standard drug ranitidine (Figure $5 b$ ). Thus, RI significantly blocked the activation of COX-2 expression in the gastric mucosal inflammatory area and reduced the inflammatory activity. 
(a)

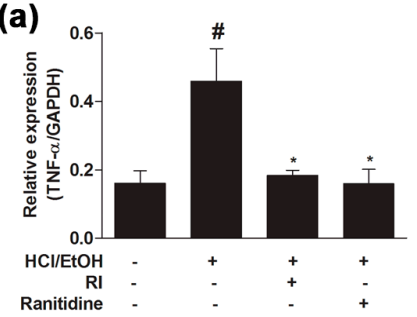

(d)

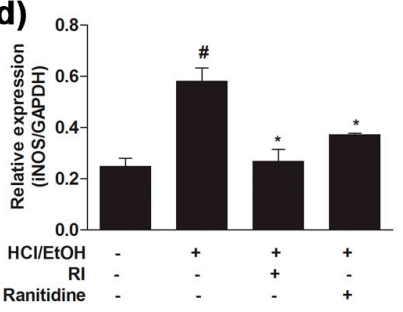

(b)

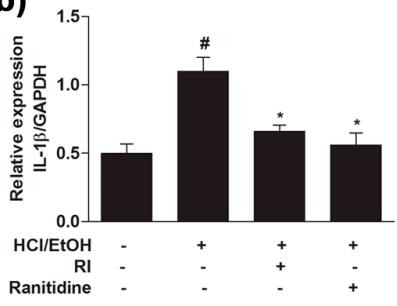

(e)

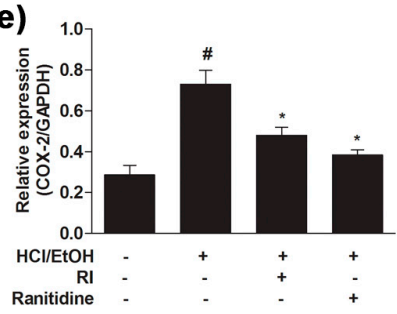

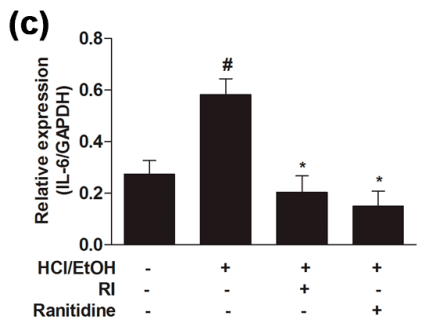

Figure 4. Protective role of RI on gene expression of pro-inflammatory cytokines in gastric tissue. In $\mathrm{HCl} / \mathrm{EtOH}$-treated mice, gene expression level of: (a) TNF- $\alpha$; (b) $I L-1 \beta$; (c) IL-6; (d) iNOS; and (e) COX-2 were significantly upregulated, whereas pretreatment with the RI markedly downregulated the gene expression level as related to ranitidine. \# $p<0.05$ when compared with control and * $p<0.05$ when compared with $\mathrm{HCl} / \mathrm{EtOH}$. Data are expressed as mean $\pm \mathrm{SEM}$.

(a)

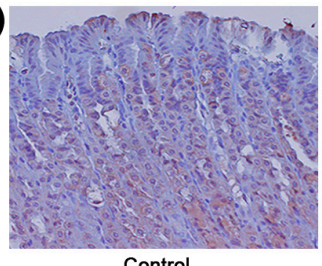

Control

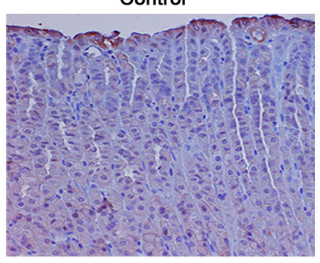

$\mathrm{HCl} / \mathrm{EtOH}+\mathrm{RI}$

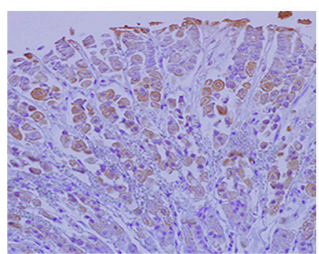

$\mathrm{HCl} / \mathrm{EtOH}$

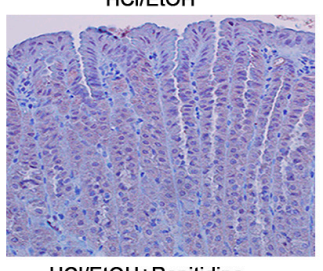

HCIEEtOH+Ranitidine (b)

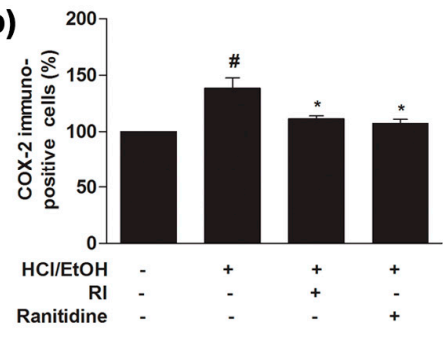

Figure 5. Protective role of RI on COX-2 immunoreactivity in the gastric tissue: (a) COX-2 expression in gastric mucosal epithelial cells; and (b) COX-2 positive immune-stained cells. Scale bar, $200 \mu \mathrm{m}$. $\# p<0.05$ when compared with the control and $* p<0.05$ when compared with $\mathrm{HCl} / \mathrm{EtOH}$. Data are expressed as mean \pm SEM.

\subsection{RI Blocked the MAPK Cascade, COX-2, and NF- $\kappa B$ Activation}

To find the possible molecular mechanisms of the anti-inflammatory and gastroprotective role of RI, the protein expression related to anti-inflammation signaling pathways was evaluated. The present data showed that LPS treatment remarkably elevated the phosphorylation of MAPK family protein (ERK1/2, JNK, and p38) in RAW 264.7 cells, whereas RI pretreatment notably $(p<0.05)$ attenuated the phosphorylation of MAPK proteins (Figure 6, upper panel). Meanwhile, LPS and $\mathrm{HCl} / \mathrm{EtOH}$ treatment increased COX-2 expression in RAW 264.7 cells and gastric tissues were markedly $(p<0.05)$ blocked by RI pretreatment (Figure 6, middle panel). After LPS and $\mathrm{HCl} / \mathrm{EtOH}$ stimulation, IkB $\alpha$ and NF-kB phosphorylation were noticeably $(p<0.05)$ increased, indicating the activation of NF- $\kappa B$. However, I $\mathrm{K} \mathrm{B} \alpha$ phosphorylation and the nuclear translocation of NF- $\mathrm{KB}(\mathrm{p} 65)$ were gradually reduced $(p<0.05)$ by RI pretreatment (Figure 6, middle and lower panels). Moreover, RI alone does not seem to 
involve in the signal pathways in vitro study. Together, these results demonstrate that RI significantly inhibited the phosphorylation of MAPK cascade in RAW 264.7 cells as well as activation of COX-2, $\mathrm{I} \kappa \mathrm{B} \alpha$, and NF- $\mathrm{KB}$ in RAW 264.7 cells and gastric tissues, simultaneously.
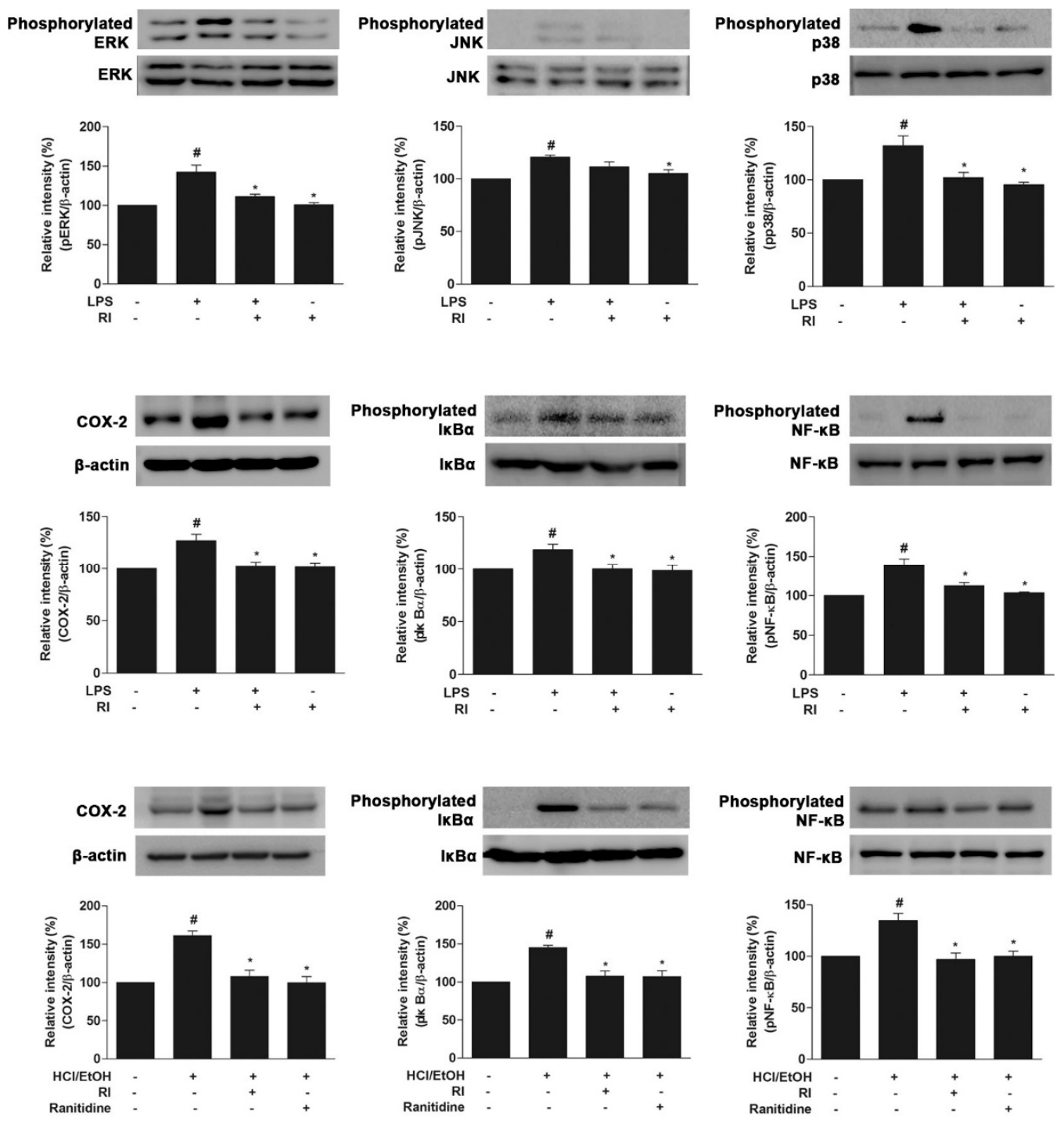

Figure 6. Protective role of RI on the MAPK cascades, COX-2 expression, and activation of I $\kappa \mathrm{B} \alpha, \mathrm{NF}-\kappa \mathrm{B}$ in RAW 264.7 cells and gastric tissue. Here, upper and middle panels represent the MAPKs (pERK1/2, pJNK, and pp38), COX-2, I $\kappa$ B $\alpha$ and NF- $\kappa$ B expression in RAW 264.7 cells and the lower panel represents the COX-2, I $\kappa \mathrm{B} \alpha$ and NF- $\kappa \mathrm{B}$ expression in the gastric tissue. The relative band intensity of target protein was measured as compared with total protein and $\beta$-actin. LPS-induced the phosphorylation of MAPK cascade, whereas pretreatment with the RI reduced the phosphorylation of MAPK cascade. LPS and $\mathrm{HCl} / \mathrm{EtOH}$ increased the COX-2 expression, kinetic phosphorylation, and degradation of $\mathrm{I} \kappa \mathrm{B} \alpha$ and phosphorylation of NF- $\mathrm{kB}$. However, pretreatment with the RI notably decreased the COX-2 expression, $\mathrm{I} \kappa \mathrm{B} \alpha$ phosphorylation, and degradation, NF- $\kappa \mathrm{B}$ translocation as related to standard drug ranitidine. $\# p<0.05$ when compared with the control and * $p<0.05$ when compared with LPS and $\mathrm{HCl} / \mathrm{EtOH}$. Data are expressed as mean \pm SEM.

\section{Discussion}

Gastrointestinal disorders are a global health problem affecting millions of people. Inflammation is a defensive biological response to harmful stimuli and infection that promotes the production of 
inflammatory mediators. Oxidative stress plays a vital role in alterations related to the pathophysiology of inflammation. Modulation of the inflammatory mediators is considered a promising strategy for facing inflammatory disease. Although RI has been traditionally used to treat inflammatory diseases, the underlying molecular mechanism of anti-inflammation properties is still not understood. The study investigated the anti-inflammatory and gastroprotective activity of RI in a model of LPS-induced inflammation in RAW 264.7 cells and $\mathrm{HCl} / \mathrm{EtOH}$-induced experimental gastric ulcer.

Antioxidants play an important role in redox mechanisms in a biological system, protecting it against inflammation and apoptosis. Phenolic and flavonoid are the most important plant secondary metabolites and have the strong antioxidant capacity $[18,19]$. Antioxidants act as oxygen scavenger capable of catalyzing the oxidative process [20]. Significant amounts of phenolic and flavonoid content were found in RI (Table 2) that may be the major donor for the anti-oxidative as well as anti-inflammatory role against gastric damage. For the possible mechanism by which RI protects against LPS-induced macrophage cell damage, these results showed that it may act through its anti-oxidative and anti-inflammatory effects (Figure 1). Treatment with the RI inhibited the LPS-induced intracellular oxidative stress (ROS) and NO production (Figure 2, upper panel). These data strongly suggest that RI could cure various inflammatory symptoms based on its anti-inflammatory properties. Tissue-related macrophages play an important role in the loss of physiological functions of the organ by releasing toxic and inflammatory molecules, such as NO and ROS [21]. The synthesis of these inflammatory molecules is responsible for the progression of various inflammatory diseases, such as gastric ulcer [22,23].

Table 2. The nucleotide sequence of the primers for qPCR.

\begin{tabular}{ccc}
\hline Gene & \multicolumn{1}{c}{ Primers Sequence $\left(\mathbf{5}^{\prime}-\mathbf{3}^{\prime}\right)$} & Genebank Accession No. \\
\hline$T N F-\alpha$ & $\begin{array}{l}\text { TTGACCTCAGCGCTGAGTTG } \\
\text { CCTGTAGCCCACGTCGTAGC }\end{array}$ & NM_013693 \\
\hline$I L-1 \beta$ & $\begin{array}{l}\text { CAGGATGAGGACATGAGCACC } \\
\text { CTCTGCAGACTCAAACTCCAC }\end{array}$ & XM_006498795 \\
\hline$I L-6$ & $\begin{array}{l}\text { GTACTCCAGAAGACCAGAGG } \\
\text { TGCTGGTGACAACCACGGCC }\end{array}$ & NM_001314054 \\
\hline \multirow{2}{*}{ CNOS } & $\begin{array}{l}\text { CCCTTCCGAAGTTTCTGGCAGCAGC } \\
\text { GGCTGTCAGAGCCTCGTGGCTTTGG }\end{array}$ & XM_006532446 \\
\hline COX-2 & $\begin{array}{l}\text { CACTACATCCTGACCCACTT } \\
\text { ATGCTCCTGCTTGAGTATGT }\end{array}$ & NM_011198 \\
\hline
\end{tabular}

The pathogenesis of ethanol-induced gastric injury is very complex and related to oxidative stress that has been confirmed by recent studies [24,25]. Gastric tissue damage is caused by an imbalance between the damage of the gastric tissue and protective factors. In addition, NO plays a complex role in gastric mucosal integrity and its synthesized independently [26]. NO level declines in patients suffering from gastric distress considerably. By increasing gastric mucosal blood flow, normal production of $\mathrm{NO}$ could retain the integrity of gastric mucosa and contribute to the defense and healing of mucosal damage, while preventing chemotaxis and adhesion of inflammatory cells to guard gastric mucosa [27]. Following gastric damage, the gastric tissue may be partially oxidized due to injury. Lipid peroxidation is the result of ROS reaction against cell membranes and produces a significant level of pro-oxidant such as MDA, which leads to oxidative gastric damage [28]. In the present study, RI markedly increased NO and decreased MDA levels in gastric mucosa, demonstrating the anti-inflammatory and antioxidant potential of RI (Figure 2, lower panel). This finding is consistent with an earlier report [27]. In this study, RI attenuated the macroscopic and histopathologic lesions in gastric mucosa and inflammatory cells influx that signifies its prospective anti-gastric ulcer activities 
(Figure 3), as also shown for the standard compound ranitidine hydrochloride, a histamine-2 receptor antagonist clinically recommended for the treatment of gastric ulcer [29]. The ethanol-induced gastric lesion is a key experimental model commonly used for likely anti-gastric ulcer activity since ethanol is thought to be a leading cause of gastric ulcer [30,31]. Ethanol has been revealed to cause hemorrhagic gastric lesions characterized by mucosal friability and infiltration of inflammatory cells [32]. Reduction of the infiltration of inflammatory cells (neutrophil) has been considered to be a vital anti-inflammatory mechanism by which effective anti-gastric-ulcer medicine protects against mucosal injuries [33].

Pro-inflammatory cytokines and enzymes such as TNF- $\alpha, I L-1 \beta, I L-6, i N O S$ and COX-2 genes in the tissue may be used as biomarkers of gastric visceral damage. Following inflammatory stimuli, inflammatory mediators have been elevated to prompt deleterious effect in the stomach. In this study, increased production of inflammatory cytokines in ulcerated gastric tissue can be attributed to the damaging effect of ethanol. A high level of cytokines triggers neutrophils, lymphocytes, and monocytes at the inflammatory site; these, in turn, start a different oxidative disturbance, toxic metabolites, and lysosomal enzymes liable for local tissue damage in gastric ulcer [34]. Present study observed that RI remarkably suppressed the pro-inflammatory cytokine production in gastric tissue (Figure 4). The inhibition of NF- $\mathrm{KB}$ is a primary mechanism for RI suppression of gastric ulcer since the expression of various pro-inflammatory cytokines including TNF- $\alpha$ is mainly regulated by the transcription of NF-kB [35].

Inflammation is a physiological and immunological response triggered by both cell and tissue injury that is primarily controlled by a MAPK cascade signaling pathway [36]. MAPKs are kinases that are responsible for most cellular responses to inflammatory cytokines and external stress signals, and these kinases are essential for the regulation of the production of various inflammation mediators [37,38]. MAPK cascade pathway is activated by inflammatory stimuli such as LPS. MAPK comprising ERK, JNK, and p38, is controlled in response to the triggering of extracellular signal cytoskeletal proteins, nuclear transcription factors and the stabilization of cytokines gene. Experimental results revealed that LPS gradually upregulated the phosphorylation of MAPKs, and these phosphorylated MAPKs was notably inhibited by pretreatment with RI, resulting in the elevation of antioxidant response element of RI regulated phase II enzymes, which are involved in cellular protection mechanism (Figure 6, upper panel). Similarly, COX-2 is an important factor which plays key roles in the pathogenesis of inflammation. The protein expression of COX-2 significantly increased after LPS and $\mathrm{HCl} / \mathrm{EtOH}$ treatment. However, the expression of COX-2 was decreased markedly by RI treatment (Figure 6, middle and lower panels). The immunohistochemical data showed that RI pretreatment markedly blocked the COX-2 localization in the gastric mucosal epithelium cells of the inflammatory area indicating that COX-2 was involved in the inhibition of inflammatory cells activation and mitigates the oxidative stress, and improve the healing process in the gastric mucosa (Figure 5).

It is known that pro-inflammatory cytokines are regulated by NF-kB signaling pathway [39]. The activation of NF- $\mathrm{KB}$ is induced by ROS and NO produced from macrophages following exposure of LPS and it depends on the phosphorylation and degradation of the corresponding upstream factor I $\kappa \mathrm{B} \alpha$. Similarly, gastric damages lead to the production of free radicals that prompt the migration and accumulation of macrophages and leukocytes in the damaged sites and the release of pro-inflammatory mediators [40]. The NF- $\kappa B$ dimers are normally sequestered in the cytosol by binding to the IкB inhibitory protein. The previous study reported that ethanol stimulation activates NF- $\kappa \mathrm{B}$, which leads to phosphorylation of IkB $\alpha$ and p50/p65 heterodimer [27]. These p50/p65 dimers enhanced by phosphorylated I $\mathrm{K} \beta \alpha$ promote gene expression of pro-inflammatory cytokines, which translocate to the nucleus [41]. In the present study, the results showed that RI significantly inhibited phosphorylation

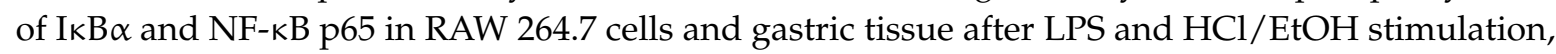
respectively (Figure 6, middle and lower panels). The study indicates that RI may inhibit early steps of inflammation and modulate upregulation of pro-inflammatory cytokines through suppression of NF- $\mathrm{KB}$ translocation. 


\section{Materials and Methods}

\subsection{Chemicals and Antibodies}

LPS, MTT, penicillin/streptomycin, trypsin-EDTA, hematoxylin, eosin, and protease inhibitor were purchased from Sigma-Aldrich (St. Louis, MO, USA). DMEM, FBS, and other cell culture reagents were supplied by Gibco (Carlsbad, CA, USA). DMSO was obtained from Bioshop (Burlington, ON, Canada). RNA extraction kit (RiboEx and Hybrid-R) was bought from Gene All (Seoul, Korea). Griess reagent, cDNA synthesis kit (ReverTra Ace qPCR RT Kit), T-PER, and BCA protein assay kit were purchased from Thermo Scientific (Waltham, MA, USA). SYBR Green qPCR Kit obtained from TOYOBO (Tokyo, Japan). Primary antibodies ERK1/2, JNK, p38, COX-2, IkB $\alpha$, NF- $\mathrm{B}$, and $\beta$-actin were supplied by Cell Signaling (Danvers, MA, USA). Secondary antibody (goat anti-rabbit immunoglobulin $\mathrm{g}$ horseradish peroxidase) was provided by Santa Cruz (Dallas, TX, USA). WESTSAVE gold ECL detection kit was obtained from Abfrontire (Seoul, Korea). TBARS assay kit by Cayman (Ann Arbor, MI, USA). ROS-Glo $\mathrm{H}_{2} \mathrm{O}_{2}$ assay kit was supplied by Promega (Madison, WI, USA). Zoletil 50 was bought from Virbac (Carros, France).

\subsection{Collection and Preparation of Rabdosia Inflexa Extract}

The aerial part of RI was collected from the Jiri mountain area in the southern part of Korea and was authenticated from its microscopic and macroscopic features by the Korean Institute of Oriental Medicine (KIOM). We prepared RI extract according to the previously described method [42]. Briefly, the aerial parts were chopped and dried completely. The extract was prepared by maceration of the sample with $70 \%$ ethanol (twice for $2 \mathrm{~h}$ reflux), and then the filtered extract was concentrated under vacuum centrifuge and dehydrated with a lyophilizer. The powder extract was liquefied in dimethyl sulfoxide (DMSO) and was sterilized using a $0.22 \mu \mathrm{m}$ syringe filter. RI was dissolved in $0.04 \%$ DMSO in media for cell culture experiments and 0.1\% DMSO in saline for oral gavage. The dried extract was kept at $-20{ }^{\circ} \mathrm{C}$. The study was conducted using a single batch of extract to avoid batch-to-batch variation and maximize the product constancy.

\subsection{Phytochemical Analysis}

Total phenolic and flavonoid content of RI extract was measured using Folin-Ciocalteu (FC) method according to the previously described method [43].

\subsection{RAW 264.7 Cells Culture}

Mouse macrophage RAW 264.7 cells were cultured in Dulbecco modified Eagle medium (DMEM) enriched with $10 \%$ fetal bovine serum (FBS) and $1 \%$ penicillin and streptomycin in a $5 \% \mathrm{CO}_{2}$ humidified incubator at $37^{\circ} \mathrm{C}$. Cells were maintained as a monolayer and subcultured once cells reached about $90 \%$ confluency in the culture flask.

\subsection{Cell Viability and Morphological Study}

Cell viability was detected using a 3-(4,5-dimethyl-thiazol-2-yl)-2,5-diphenyltetrazolium bromide (MTT) assay, following a prescribed method [34]. Briefly, RAW 264.7 cells $\left(1 \times 10^{6}\right.$ cells $\left./ \mathrm{mL}\right)$ were cultured overnight. To determine the cytotoxicity, cells were treated with RI (50, 100, 200, 400, and $800 \mu \mathrm{g} / \mathrm{mL})$ for $24 \mathrm{~h}$. In contrast, measuring the cell viability, cells were pretreated with RI (100, 200, and $400 \mu \mathrm{g} / \mathrm{mL})$ for $1 \mathrm{~h}$ and co-treated with LPS $(0.5 \mu \mathrm{g} / \mathrm{mL})$ and RI for another $24 \mathrm{~h}$. Moreover, for morphological evaluation of RAW 264.7 cells, the image of the cells was acquired by an inverted microscope (CKX41, Olympus, Tokyo, Japan). 


\subsection{Measurement of NO and ROS in RAW 264.7 Cells}

Mouse macrophage RAW 264.7 cells $\left(1 \times 10^{6}\right.$ cells $\left./ \mathrm{mL}\right)$ were cultured in 96 well plates. After overnight culture, cells were pretreated with RI $(100,200$. and $400 \mu \mathrm{g} / \mathrm{mL})$ for $1 \mathrm{~h}$ and were then co-treated with LPS $(0.5 \mu \mathrm{g} / \mathrm{mL})$ and RI for $24 \mathrm{~h}$. NO, and ROS activity was measured by Griess reagent and a ROS-Glo $\mathrm{H}_{2} \mathrm{O}_{2}$ assay kit according to the manufacturer's recommendation. Intracellular ROS and NO levels were measured at $570 \mathrm{~nm}$ by the tunable Versa max microplate reader.

\subsection{Mice Management and HCl/EtOH-Induced Gastric Ulcer Model}

Six-week-old ICR mice were handled in accordance with the published method [34] and in accordance with the guide for the care and use of laboratory animals (Eighth Edition, 2011, published by The National Academies Press, Washington, DC, USA) and Institutional Animal Care and Use Committee (IACUC; CBNU 2017-0126) of the Chonbuk National University Laboratory Animal Center in Korea. An experimental gastric ulcer model in mice was induced using $\mathrm{HCl} / \mathrm{EtOH}$ [44]. Forty ICR mice were randomly divided into four groups. Mice fasted overnight before the experiment. Fasted mice were orally given RI $(400 \mathrm{mg} / \mathrm{kg})$ and ranitidine $(40 \mathrm{mg} / \mathrm{kg})$ in respected groups for $1 \mathrm{~h}$. After $1 \mathrm{~h}, 60 \% \mathrm{EtOH}$ in $150 \mathrm{mM} \mathrm{HCl}(10 \mu \mathrm{L} / \mathrm{g})$ was given orally. Control mice were treated with normal saline. Mice were anesthetized with Zoletil $50(10 \mathrm{mg} / \mathrm{kg}) 1 \mathrm{~h}$ after administration of $\mathrm{HCl} / \mathrm{EtOH}$ and samples were collected for experimental analysis.

\subsection{Gross and Histopathology of Gastric Mucosal Tissue}

To evaluate the gross and histological changes in glandular stomach tissue, we followed previous study [34]. For quantifying the degree of gross and histological lesions index, we followed a prescribed method with slight modification [45]. Briefly, the gross lesions of gastric mucosa were measured using following formula; (number of lesions of type I) + (number of lesions of type II) $\times 2+$ (number of lesions of type III) $\times 3$. Here, the gross lesions were characterized by: the presence of single submucosal punctiform hemorrhage, edema, type I; the presence of submucosal hemorrhagic lesions with slight erosions, type II; and the presence of deep ulcer with erosions and invasive lesions, type III. Besides, the histological lesions of gastric mucosa were measured using following formula; ( $\%$ type I lesion) $\times$ $1+(\%$ type II lesion $) \times 2+(\%$ type III lesion $) \times 3$. Here, the histological lesions were characterized by: gastric mucosal cells appeared intact and had a normal shape, type 0 lesion; surface epithelial cells and the uppermost 2 or 3 cells lining the glands were damaged, type I damage; damage greater than I but involving $<50 \%$ of the thickness of the gastric mucosa, type II damage; and damage involving $>50 \%$ of the thickness of the gastric mucosa, type III damage.

\subsection{Analysis of Lipid Peroxidation and NO Production}

Malondialdehyde (MDA) and NO are important indicators of oxidative stress. The gastric tissue was homogenized and centrifuged at $10,000 \mathrm{rpm}$ at $4{ }^{\circ} \mathrm{C}$ for $10 \mathrm{~min}$. The supernatant was collected and kept at $-80^{\circ} \mathrm{C}$ for experimental analysis. MDA and $\mathrm{NO}$ concentration were measured in the gastric tissue samples according to the commercial kit instructions.

\subsection{RNA Extraction and Quantitative Real-Time Polymerase Chain Reaction (qPCR)}

The RNA was extracted from a gastric tissue according to the manufacturer's instructions. The concentration of total RNA was quantified with the BioSpec-nano spectrophotometer (Shimadzu Biotech, Tokyo, Japan) at a $260 / 280 \mathrm{~nm}$ ratio. For complementary DNA (cDNA) synthesis, total RNA $(3 \mu \mathrm{g})$ was used, and cDNA synthesis was maintained according to the manufacturer's instructions. qPCR was performed SYBR Green Real-Time PCR master mix according to Roche LightCycler ${ }^{\mathrm{TM}}$. Relative expression of target genes was normalized to the reference gene: glyceraldehyde 3-phosphate dehydrogenase (GAPDH). The sequences of the primers (Bioneer, Daejeon, Korea) used are shown in Table 2 [46]. 


\subsection{Immunohistochemical (IHC) Analysis}

COX-2 immunopositive cells expression in the gastric tissue was performed using according to Vectastain $A B C$ kit recommendations. Briefly, paraffin section was deparaffinized in xylene and hydrated in ethanol. Citrate buffer was used for antigen retrieval and $3 \%$ hydrogen peroxide $\left(\mathrm{H}_{2} \mathrm{O}_{2}\right)$ was used for inactivating the endogenous peroxidase activity. Tissue was blocked with normal serum for $1 \mathrm{~h}$. Anti-rabbit monoclonal COX-2 antibody (dilution 1:200) was incubated overnight at $4{ }^{\circ} \mathrm{C}$. Subsequently, the section was incubated with biotinylated secondary antibody for $1 \mathrm{~h}$ and Vectastain $A B C$ reagent for $30 \mathrm{~min}$ at room temperature. The sections were incubated with diaminobenzidine (DAB) in the dark until brown color development. After counterstain, the section was dehydrated in ethanol, cleared in xylene and mounted on a glass slide. The section was imaged at a fixed $100 \times$ magnification using Leica DM2500 microscope (Leica Microsystems, Wetzlar, Germany).

\subsection{Western Blot Analysis}

RAW 264.7 cells and gastric tissue were harvested and washed twice with ice-cold PBS. Cells and tissues were lysed by the lysis buffer; radioimmunoprecipitation assay buffer (RIPA), and/or tissue protein extraction reagent (T-PER), phenylmethanesulfonyl fluoride (PMSF), sodium orthovanadate $\left(\mathrm{Na}_{3} \mathrm{VO}_{4}\right)$, and protease inhibitor cocktail. The total concentration of protein of lysate cells and tissues were measured with a bicinchoninic acid (BCA) protein assay protein kit. An equal amount of protein was separated by $10-12 \%$ sodium dodecyl sulfate-polyacrylamide gel electrophoresis (SDS-PAGE) and transferred to a nitrocellulose membrane. The membrane was incubated with blocking serum; $5 \%$ bovine serum albumin (BSA) in Tris-buffered saline with tween twenty (TBST) for $2 \mathrm{~h}$ at room temperature and by primary antibodies for overnight at $4{ }^{\circ} \mathrm{C}$. Then, the blot was washed and incubated with secondary antibodies for $2 \mathrm{~h}$. Bands were detected using an enhanced chemiluminescence (ECL) detection kit, and bands images were taken by a LAS-400 image system, (GE Healthcare, Little Chalfont, $\mathrm{UK}) ; \beta$-actin was used as the reference antibody.

\subsection{Statistical Analysis}

Data were analyzed with Graph Pad Prism 5.0 (Graph Pad Software, Inc., San Diego, CA, USA) and are expressed as mean \pm standard error (SEM). Statistical analyses were assessed by analysis of variance (ANOVA) followed by Bonferroni post-hoc tests. The minimum statistical significance was considered to be $p<0.05$ for all analyses.

\section{Conclusions}

RI mitigates inflammation and maintains normal gastric mucosal integrity. The present study validates that RI protects against inflammation and gastric ulcer by mitigating the inflammation response and oxidative stress via downregulation of the pro-inflammatory cytokines mediated by MAPK/NF-KB signaling pathways. Therefore, RI could be a promising phytomedicine and has advantages for prospective clinical applications in the future for an oxidative stress-mediated gastric ulcer.

Acknowledgments: This research was supported by Basic Science Research Program through the National Research Foundation of Korea funded by the Ministry of Education (2017R1D1A1B03035765) and Biomedical Research Institute, Chonbuk National University Hospital.

Author Contributions: Md Rashedunnabi Akanda and Byung-Yong Park conceived and designed the study. Md Rashedunnabi Akanda performed the experiment, analyzed the data and wrote the original manuscript. Md Rashedunnabi Akanda, In-Shik Kim, Dongchoon Ahn, Hyun-Jin Tae, Hyeon-Hwa Nam, Byung-Kil Choo, Kyunghwa Kim and Byung-Yong Park read and approved the final version of the manuscript.

Conflicts of Interest: The authors declare no conflict of interest. 


\section{References}

1. Rehm, J. The risks associated with alcohol use and alcoholism. Alcohol Res. Health 2011, 34, $135-143$. [PubMed]

2. Tarnawski, A.S.; Ahluwalia, A.; Jones, M.K. Increased susceptibility of aging gastric mucosa to injury: The mechanisms and clinical implications. World J. Gastroenterol. 2014, 20, 4467-4482. [CrossRef] [PubMed]

3. Orywal, K.; Szmitkowski, M. Alcohol dehydrogenase and aldehyde dehydrogenase in malignant neoplasms. Clin. Exp. Med. 2017, 17, 131-139. [CrossRef] [PubMed]

4. Kwiecien, S.; Jasnos, K.; Magierowski, M.; Sliwowski, Z.; Pajdo, R.; Brzozowski, B.; Mach, T.; Wojcik, D.; Brzozowski, T. Lipid peroxidation, reactive oxygen species and antioxidative factors in the pathogenesis of gastric mucosal lesions and mechanism of protection against oxidative stress-Induced gastric injury. J. Physiol. Pharmacol. 2014, 65, 613-622. [PubMed]

5. Singh, P.; Vishwakarma, S.P.; Singh, R.L. Antioxidant, oxidative DNA damage protective and antimicrobial activities of the plant Trigonella foenum-graecum. J. Sci. Food Agric. 2014, 94, 2497-2504. [CrossRef] [PubMed]

6. Allavena, P.; Garlanda, C.; Borrello, M.G.; Sica, A.; Mantovani, A. Pathways connecting inflammation and cancer. Curr. Opin. Genet. Dev. 2008, 18, 3-10. [CrossRef] [PubMed]

7. El-Maraghy, S.A.; Rizk, S.M.; Shahin, N.N. Gastroprotective effect of crocin in ethanol-induced gastric injury in rats. Chem. Biol. Interact. 2015, 229, 26-35. [CrossRef] [PubMed]

8. Akira, S. Toll-like receptors: Lessons from knockout mice. Biochem. Soc. Trans. 2000, 28, 551-556. [CrossRef] [PubMed]

9. Song, X.; Zhang, W.; Wang, T.; Jiang, H.; Zhang, Z.; Fu, Y.; Yang, Z.; Cao, Y.; Zhang, N. Geniposide plays an anti-inflammatory role via regulating TLR4 and downstream signaling pathways in lipopolysaccharide-induced mastitis in mice. Inflammation 2014, 37, 1588-1598. [CrossRef] [PubMed]

10. Zhang, Y.L.; Dong, C. MAP kinases in immune responses. Cell. Mol. Immunol. 2005, 2, 20-27. [PubMed]

11. Ryan, S.; McNicholas, W.T.; Taylor, C.T. A critical role for p38 map kinase in NF-kappaB signaling during intermittent hypoxia/reoxygenation. Biochem. Biophys. Res. Commun. 2007, 355, 728-733. [CrossRef] [PubMed]

12. Dambrova, M.; Zvejniece, L.; Skapare, E.; Vilskersts, R.; Svalbe, B.; Baumane, L.; Muceniece, R.; Liepinsh, E. The anti-inflammatory and antinociceptive effects of NF-kappaB inhibitory guanidine derivative ME10092. Int. Immunopharmacol. 2010, 10, 455-460. [CrossRef] [PubMed]

13. Nakajima, H.; Itokawa, H.; Ikuta, A. [Studies on the constituents of the flower of Camellia japonica (2)]. Yakugaku Zasshi 1984, 104, 157-161. [CrossRef] [PubMed]

14. Fujita, T.; Takeda, Y.; Yuasa, E.; Okamura, A.; Shingu, T.; Yokoi, T. Structure of Inflexinol, a New Cyto-Toxic Diterpene from Rabdosia-Inflexa. Phytochemistry 1982, 21, 903-905. [CrossRef]

15. Kubo, I.; Nakanishi, K.; Kamikawa, T.; Isobe, T.; Kubota, T. Structure of Inflexin. Chem. Lett. 1977, 6, 99-102. [CrossRef]

16. Ahn, D.W.; Ryu, J.K.; Kim, J.; Kim, Y.T.; Yoon, Y.B.; Lee, K.; Hong, J.T. Inflexinol reduces severity of acute pancreatitis by inhibiting nuclear factor-kappaB activation in cerulein-induced pancreatitis. Pancreas 2013, 42, 279-284. [CrossRef] [PubMed]

17. Salama, S.M.; Gwaram, N.S.; AlRashdi, A.S.; Khalifa, S.A.; Abdulla, M.A.; Ali, H.M.; El-Seedi, H.R. A Zinc Morpholine Complex Prevents HCl/Ethanol-Induced Gastric Ulcers in a Rat Model. Sci. Rep. 2016, 6, 29646. [CrossRef] [PubMed]

18. Lin, D.R.; Xiao, M.S.; Zhao, J.J.; Li, Z.H.; Xing, B.S.; Li, X.D.; Kong, M.Z.; Li, L.Y.; Zhang, Q.; Liu, Y.W.; et al. An Overview of Plant Phenolic Compounds and Their Importance in Human Nutrition and Management of Type 2 Diabetes. Molecules 2016, 21, 1374. [CrossRef] [PubMed]

19. Mierziak, J.; Kostyn, K.; Kulma, A. Flavonoids as Important Molecules of Plant Interactions with the Environment. Molecules 2014, 19, 16240-16265. [CrossRef] [PubMed]

20. Dzoyem, J.P.; Eloff, J.N. Anti-inflammatory, anticholinesterase and antioxidant activity of leaf extracts of twelve plants used traditionally to alleviate pain and inflammation in South Africa. J. Ethnopharmacol. 2015, 160, 194-201. [CrossRef] [PubMed] 
21. Kim, M.J.; Kadayat, T.; Kim, D.E.; Lee, E.S.; Park, P.H. TI-I-174, a Synthetic Chalcone Derivative, Suppresses Nitric Oxide Production in Murine Macrophages via Heme Oxygenase-1 Induction and Inhibition of AP-1. Biomol. Ther. 2014, 22, 390-399. [CrossRef] [PubMed]

22. Li, B.; Alli, R.; Vogel, P.; Geiger, T.L. IL-10 modulates DSS-induced colitis through a macrophage-ROS-NO axis. Mucosal Immunol. 2014, 7, 869-878. [CrossRef] [PubMed]

23. Yang, W.S.; Jeong, D.; Yi, Y.S.; Lee, B.H.; Kim, T.W.; Htwe, K.M.; Kim, Y.D.; Yoon, K.D.; Hong, S.; Lee, W.S.; et al. Myrsine seguinii ethanolic extract and its active component quercetin inhibit macrophage activation and peritonitis induced by LPS by targeting to Syk/Src/IRAK-1. J. Ethnopharmacol. 2014, 151, 1165-1174. [CrossRef] [PubMed]

24. Xie, M.; Chen, H.; Nie, S.; Tong, W.; Yin, J.; Xie, M. Gastroprotective effect of gamma-aminobutyric acid against ethanol-induced gastric mucosal injury. Chem. Biol. Interact. 2017, 272, 125-134. [CrossRef] [PubMed]

25. Lee, J.S.; Oh, T.Y.; Kim, Y.K.; Baik, J.H.; So, S.; Hahm, K.B.; Surh, Y.J. Protective effects of green tea polyphenol extracts against ethanol-induced gastric mucosal damages in rats: Stress-responsive transcription factors and MAP kinases as potential targets. Mutat. Res. Fundam. Mol. Mech. Mutagen. 2005, 579, 214-224. [CrossRef] [PubMed]

26. Calatayud, S.; Barrachina, D.; Esplugues, J.V. Nitric oxide: Relation to integrity, injury, and healing of the gastric mucosa. Microsc. Res. Tech. 2001, 53, 325-335. [CrossRef] [PubMed]

27. Chen, S.; Zhao, X.; Sun, P.; Qian, J.; Shi, Y.; Wang, R. Preventive effect of Gardenia jasminoides on $\mathrm{HCl} /$ ethanol induced gastric injury in mice. J. Pharmacol. Sci. 2017, 133, 1-8. [CrossRef] [PubMed]

28. Yu, T.; Yang, Y.; Kwak, Y.S.; Song, G.G.; Kim, M.Y.; Rhee, M.H.; Cho, J.Y. Ginsenoside Rc from Panax ginseng exerts anti-inflammatory activity by targeting TANK-binding kinase 1 /interferon regulatory factor-3 and p38/ATF-2. J. Ginseng Res. 2017, 41, 127-133. [CrossRef] [PubMed]

29. Park, J.G.; Kim, S.C.; Kim, Y.H.; Yang, W.S.; Kim, Y.; Hong, S.; Kim, K.H.; Yoo, B.C.; Kim, S.H.; Kim, J.H.; et al. Anti-Inflammatory and Antinociceptive Activities of Anthraquinone-2-Carboxylic Acid. Mediat. Inflamm. 2016, 2016, 1903849. [CrossRef] [PubMed]

30. Liu, Y.; Tian, X.; Gou, L.; Fu, X.; Li, S.; Lan, N.; Yin, X. Protective effect of 1-citrulline against ethanol-induced gastric ulcer in rats. Environ. Toxicol. Pharmacol. 2012, 34, 280-287. [CrossRef] [PubMed]

31. Boligon, A.A.; de Freitas, R.B.; de Brum, T.F.; Waczuk, E.P.; Klimaczewski, C.V.; de Avila, D.S.; Athayde, M.L.; de Freitas Bauermann, L. Antiulcerogenic activity of Scutia buxifolia on gastric ulcers induced by ethanol in rats. Acta Pharm. Sin. B 2014, 4, 358-367. [CrossRef] [PubMed]

32. Park, S.W.; Oh, T.Y.; Kim, Y.S.; Sim, H.; Park, S.J.; Jang, E.J.; Park, J.S.; Baik, H.W.; Hahm, K.B. Artemisia asiatica extracts protect against ethanol-induced injury in gastric mucosa of rats. J. Gastroenterol. Hepatol. 2008, 23, 976-984. [CrossRef] [PubMed]

33. Mei, X.; Xu, D.; Xu, S.; Zheng, Y.; Xu, S. Novel role of Zn(II)-curcumin in enhancing cell proliferation and adjusting proinflammatory cytokine-mediated oxidative damage of ethanol-induced acute gastric ulcers. Chem. Biol. Interact. 2012, 197, 31-39. [CrossRef] [PubMed]

34. Akanda, M.R.; Park, B.Y. Involvement of MAPK/NF-kappaB signal transduction pathways: Camellia japonica mitigates inflammation and gastric ulcer. Biomed. Pharmacother. 2017, 95, 1139-1146. [CrossRef] [PubMed]

35. Li, W.; Huang, H.; Niu, X.; Fan, T.; Mu, Q.; Li, H. Protective effect of tetrahydrocoptisine against ethanol-induced gastric ulcer in mice. Toxicol. Appl. Pharmacol. 2013, 272, 21-29. [CrossRef] [PubMed]

36. Ci, X.; Ren, R.; Xu, K.; Li, H.; Yu, Q.; Song, Y.; Wang, D.; Li, R.; Deng, X. Schisantherin A exhibits anti-inflammatory properties by down-regulating NF-kappaB and MAPK signaling pathways in lipopolysaccharide-treated RAW 264.7 cells. Inflammation 2010, 33, 126-136. [CrossRef] [PubMed]

37. Wei, S.G.; Yu, Y.; Weiss, R.M.; Felder, R.B. Endoplasmic reticulum stress increases brain MAPK signaling, inflammation and renin-angiotensin system activity and sympathetic nerve activity in heart failure. Am. J. Physiol. Heart Circ. Physiol. 2016, 311, H871-H880. [CrossRef] [PubMed]

38. Jin, X.; Han, J.; Yang, S.; Hu, Y.; Liu, H.; Zhao, F. 11-O-acetylcyathatriol inhibits MAPK/p38-mediated inflammation in LPS-activated RAW 264.7 macrophages and has a protective effect on ethanol-induced gastric injury. Mol. Med. Rep. 2016, 14, 874-880. [CrossRef] [PubMed]

39. Liang, Y.; Zhou, Y.; Shen, P. NF-kappaB and its regulation on the immune system. Cell. Mol. Immunol. 2004, 1, 343-350. [PubMed] 
40. Kang, J.W.; Yun, N.; Han, H.J.; Kim, J.Y.; Kim, J.Y.; Lee, S.M. Protective Effect of Flos Lonicerae against Experimental Gastric Ulcers in Rats: Mechanisms of Antioxidant and Anti-Inflammatory Action. Evid. Based Complement. Altern. Med. 2014, 2014. [CrossRef] [PubMed]

41. Hinz, M.; Scheidereit, C. The IkappaB kinase complex in NF-kappaB regulation and beyond. EMBO Rep. 2014, 15, 46-61. [CrossRef] [PubMed]

42. Akanda, M.; Tae, H.-J.; Kim, I.-S.; Ahn, D.; Tian, W.; Islam, A.; Nam, H.-H.; Choo, B.-K.; Park, B.-Y. Hepatoprotective Role of Hydrangea macrophylla against Sodium Arsenite-Induced Mitochondrial-Dependent Oxidative Stress via the Inhibition of MAPK/Caspase-3 Pathways. Int. J. Mol. Sci. 2017, 18, 1482. [CrossRef] [PubMed]

43. Jing, L.; Ma, H.; Fan, P.; Gao, R.; Jia, Z. Antioxidant potential, total phenolic and total flavonoid contents of Rhododendron anthopogonoides and its protective effect on hypoxia-induced injury in PC12 cells. BMC Complement. Altern. Med. 2015, 15, 287. [CrossRef] [PubMed]

44. Yang, Y.; Yu, T.; Lee, Y.G.; Yang, W.S.; Oh, J.; Jeong, D.; Lee, S.; Kim, T.W.; Park, Y.C.; Sung, G.H.; et al. Methanol extract of Hopea odorata suppresses inflammatory responses via the direct inhibition of multiple kinases. J. Ethnopharmacol. 2013, 145, 598-607. [CrossRef] [PubMed]

45. Nam, S.Y.; Kim, N.; Lee, C.S.; Choi, K.D.; Lee, H.S.; Jung, H.C.; Song, I.S. Gastric mucosal protection via enhancement of MUC5AC and MUC6 by geranylgeranylacetone. Dig. Dis. Sci. 2005, 50, 2110-2120. [CrossRef] [PubMed]

46. Yang, Y.; Yu, T.; Jang, H.J.; Byeon, S.E.; Song, S.Y.; Lee, B.H.; Rhee, M.H.; Kim, T.W.; Lee, J.; Hong, S.; et al. In vitro and in vivo anti-inflammatory activities of Polygonum hydropiper methanol extract. J. Ethnopharmacol. 2012, 139, 616-625. [CrossRef] [PubMed]

(C) 2018 by the authors. Licensee MDPI, Basel, Switzerland. This article is an open access article distributed under the terms and conditions of the Creative Commons Attribution (CC BY) license (http:/ / creativecommons.org/licenses/by/4.0/). 